\title{
Corrosion at the Polymer-Metal Interface in Artificial Seawater Solutions
}

\author{
Amelia M. Anderson-Wile, ${ }^{1}$ Bradley M. Wile, ${ }^{1}$ Qiang Wen, ${ }^{2}$ and Hui Shen ${ }^{2}$ \\ ${ }^{1}$ Department of Chemistry and Biochemistry, Ohio Northern University, Ada, OH 45810, USA \\ ${ }^{2}$ Department of Mechanical Engineering, Ohio Northern University, Ada, OH 45810, USA
}

Correspondence should be addressed to Hui Shen, h-shen@onu.edu

Received 20 September 2012; Accepted 8 December 2012

Academic Editor: W. Ke

Copyright (C 2012 Amelia M. Anderson-Wile et al. This is an open access article distributed under the Creative Commons Attribution License, which permits unrestricted use, distribution, and reproduction in any medium, provided the original work is properly cited.

\begin{abstract}
Polymer components for liquid sealing applications are employed in a variety of potentially corrosive environments, such as seawater. Frequently, corrosion of the metal is found at or adjacent to the rubber-metal interface rather than at a noncontact area. The corrosion of different metal alloys (titanium, bronze, nickel, aluminum, 316 stainless steel, and 4130 steel) in combination with rubber O-rings (Buna-N and EPDM) of varying internal diameters and cross-sectional shapes in seawater over a period of four years is described herein. The corrosion of some metals (i.e., 4130 stainless steel) was found to be accelerated through interaction with Buna-N rubber O-rings. Theories to account for corrosion at the polymer-metal interface, especially with respect to polymer composition and O-ring size and shape, are discussed.
\end{abstract}

\section{Introduction}

By virtue of the high concentration of electrolytes such as $\mathrm{NaCl}$ and $\mathrm{MgCl}_{2}$ in saltwater solutions, corrosion of metal components is often a concern. In particular, the corrosion of stainless steel alloys in marine environments has been the subject of much study [1-5]. In addition to metal alloys, mechanical seals such as O-rings are often used in marine environments to seal machine parts and prevent leakage between metal components. While it seems intuitive that the addition of a seal or flange may prevent surface corrosion by reducing the surface area of the metal in contact with the electrolyte solution, this may also lead to the formation of a stagnant region (Figure 1), in which dissolved oxygen may be depleted, leading to the formation of a crevice.

Crevice corrosion of stainless steel is important because it may significantly impact the strength of a structural material under conditions that may not otherwise lead to decomposition or material failure. Since crevice corrosion occurs in stagnant areas, often those blocked by a flange, seal, or other deposit, assessing the extent of corrosion in real time, can be challenging. Several numerical and predictive models of crevice corrosion have been proposed, and reviews of the history and theory behind successive models may be found in the literature [6].

Currently accepted theory combines aspects of critical crevice solution theory (CCST) and IR drop theory (IRDT) $[6,7]$ to arrive at a model for crevice corrosion in aqueous solution. In this model (Figure 2), dissolved oxygen diffuses to the surface of the metal, where it is reduced at the cathode to hydroxide ions (1). Oxygen reduction is maintained, with electrons generated at the anode (within the crevice region). These electrons are a byproduct of metal oxidation (2) and (3), which also results in aqueous metal ions $\left(\mathrm{Fe}^{2+}\right.$ and $\mathrm{Cr}^{3+}$ predominantly). Hydroxide ions as well as chloride ions from dissolved salt migrate into the crevice region, where metal chlorides and metal hydroxides such as $\mathrm{FeCl}_{2}$ and $\mathrm{Cr}(\mathrm{OH})_{3}$ are formed. These species may be further transformed into more familiar products, including various forms of iron and chromium oxide. The potential of the system drops as a result of several factors, including the flow of chloride and hydroxide ions in solution, the resistance of electrons to flow through the metal, and surface overpotential. Consequently, the system enters a region of active corrosion, leading to a marked increase in the rate of corrosion in the crevice. Using this model, researchers were able to predict the localized $\mathrm{pH}$ 


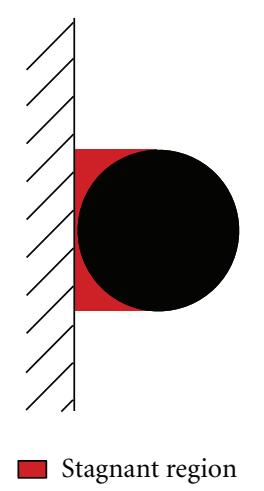

(a)

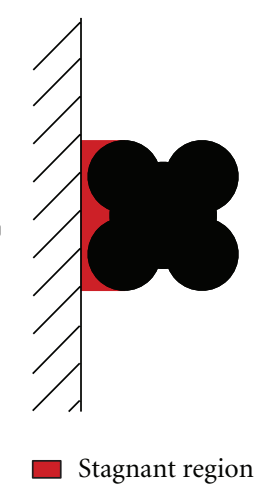

(b)
FIGURE 1: Stagnant regions formed near the polymer-metal interface for (a) round and (b) quad O-rings (cross-section shown).

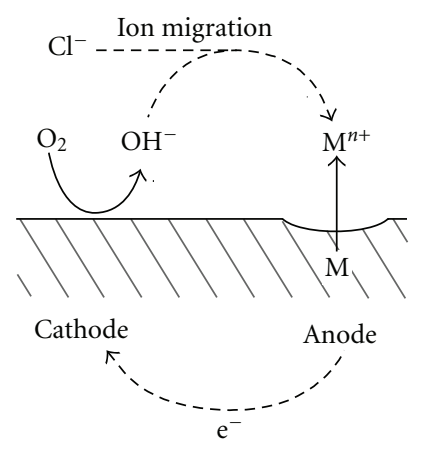

FIGURE 2: Idealized crevice, showing the transformation and migration of corrodants.

as the crevice is formed, approximating experimental data [7]:

$$
\begin{gathered}
\mathrm{O}_{2(\mathrm{~g})}+2 \mathrm{H}_{2} \mathrm{O}_{(\mathrm{l})}+4 \mathrm{e}^{-} \longrightarrow 4 \mathrm{OH}_{(\mathrm{aq})}^{-} \\
\mathrm{Fe}_{(\mathrm{s})} \longrightarrow \mathrm{Fe}_{(\mathrm{aq})}^{2+}+2 \mathrm{e}^{-} \\
\mathrm{Cr}_{(\mathrm{s})} \longrightarrow \mathrm{Cr}_{(\mathrm{aq})}^{3+}+3 \mathrm{e}^{-}
\end{gathered}
$$

Despite extensive study of the process by which stagnant regions undergo crevice corrosion, the authors are not aware of studies exploring the effect of O-ring size, polymer composition, or shape on the extent or rate of corrosion in a marine environment to date. Buna- $\mathrm{N}$ polymers, which are also commonly referred to as NBR (nitrile-butadiene rubber), are obtained from the emulsion polymerization of butadiene and acrylonitrile $[8,9]$. To increase cross-linking between polymer chains, sulfur vulcanization of Buna-N materials is often carried out resulting in enhanced retractive forces and decreased permanent deformation [10]. The strength and elasticity of Buna-N polymers as well as their resistance to many solvents, oil, and water make them useful in a variety of applications including cables, hoses, and O-rings [11]. In addition to Buna-N O-rings, EPDM materials, which are produced from the polymerization of ethylene, propylene, and an unconjugated diene, were also investigated. As with Buna- $\mathrm{N}$ polymers, sulfur vulcanization of EPDM polymers is often employed to improve mechanical properties [10]. Due to its resistance to heat, light, ozone, and polar fluids, EPDM materials can be utilized in a variety of automotive, electrical, and food processing applications $[12,13]$.

The objective of the present work is to investigate the role that polymer O-rings play in promoting corrosion at the interface with a metal substrate in an artificial marine environment. Four studies have been conducted in an artificial seawater solution over a period of four years. In Case $\mathrm{A}$, round Buna-N O-rings of varying inner diameters were employed to probe the effect of contact stress on metal corrosion. In Case B, the cross-sectional shape of Buna$\mathrm{N}$ O-rings was altered to investigate the effect of O-ring morphology and the size of the polymer-metal interface region on the corrosion of metal alloys in seawater. In Case $\mathrm{C}$, both Buna-N and EPDM O-rings were used to study the effect of the polymer composition on the rate of corrosion. In Case D, different metals including titanium, bronze, nickel, aluminum, stainless steel, and 4130 steel were compared with respect to their tendency to corrode under similar conditions. The results of each of these case studies provide information about the role of polymer components on the corrosion behavior of different metals in seawater, which may be useful in the development of marine devices.

\section{Experimental Procedure}

Experiments have been conducted to study the corrosion of different metal alloys bearing rubber O-rings in seawater. In each test, a cylindrical metal sample (with $15.9 \mathrm{~mm}$ diameter and $25.4 \mathrm{~mm}$ length) was resurfaced by grinding with $100-$ grit sandpaper, fitted with an O-ring, and immersed in an $80 \mathrm{~mL}$ beaker filled with seawater (Figure 3). The seawater solution containing approximately $3 \%$ sea salt was prepared by dissolving pacific natural sea salt from Saltworks, Inc. (Woodinville, WA) in distilled water. The beakers, each containing one sample, were sealed with plastic films to reduce vaporization. Distilled water was added regularly to keep the volume relatively constant for 4 years. Metal alloys and rubber O-rings were purchased from McMaster Carr, Inc. (Elmhurst, IL). Reagent grade sodium chloride for ${ }^{1} \mathrm{H}$ NMR spectroscopy was purchased from VWR International. Though internal and outer diameters (ID and OD) varied, all O-rings had a width of $3.2 \mathrm{~mm}$, with the exception of the Buna-N O-rings used in Case A, which had a width of $3.0 \mathrm{~mm}$. All experiments were initiated on July 30,2007 , and were checked for corrosion condition on June 15, 2011, for a total test time of approximately four years. For each test, three samples were used to ensure the repeatability of the experiment. Samples were maintained at room temperature $\left(\sim 21^{\circ} \mathrm{C}\right)$ for the duration of the experiment.

The starting inner diameter of the polymer O-rings was obtained from the online catalog of McMaster-Carr, Inc. The final inner diameter (ID) was measured immediately after removal from the metal rod using a Chicago Brand 6 inch electronic digital caliper. Time delay in the ID measurement resulted in a decrease in the ID due to the viscoelastic 


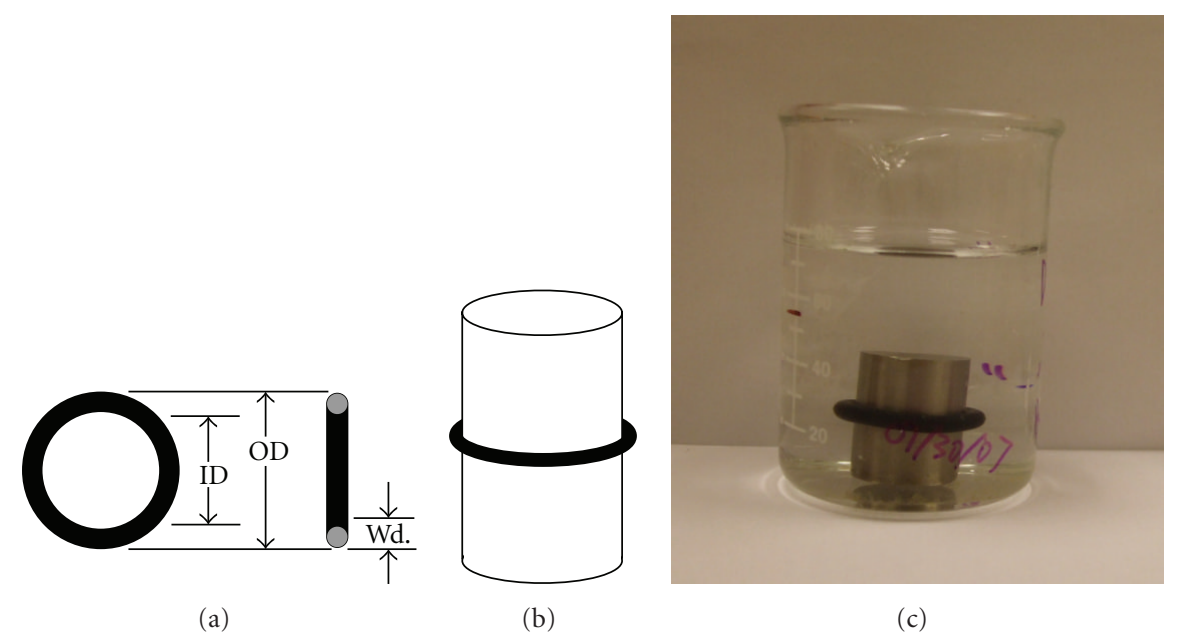

Figure 3: (a) Round O-ring with cross-section shown; (b) the O-ring mounted on a cylindrical metal sample; and (c) the metal sample, fitted with an O-ring and immersed in the artificial seawater solution.

properties of the O-rings and were therefore not included in Tables 1 and 2. To determine the dry weight of the three O-ring types, 10 new samples were weighed and averaged. The weight of the O-rings fitted to the metal alloys was determined by removing the sample from the metal, patting the O-ring dry to remove surface water and weighing on a AG204 Metler Toledo balance. The $\mathrm{pH}$ of each metal solution was found using a VWR Symphony SP20 pH meter and electrode calibrated with three VWR brand buffer solutions $\left(\mathrm{pH}=4.00,7.00\right.$, and 10.00). ${ }^{1} \mathrm{H}$ NMR characterization data were collected in $\mathrm{D}_{2} \mathrm{O}$ solution at $300 \mathrm{~K}$ on a Varian Mercury200 spectrometer operating at $199.97 \mathrm{MHz}$, with chemical shifts reported in parts per million downfield of $\mathrm{SiMe}_{4}$, and referenced to residual water.

2.1. Case A: The Effect of Contact Stress on Metal Corrosion. Round Buna-N O-rings with varying internal diameters (ID $=12,13$, or $14 \mathrm{~mm}, \mathrm{Wd} .=3 \mathrm{~mm}$ in each case) were used to probe the effect of contact stress on metal corrosion. Samples were tested after 0.7 years, immersed in the artificial seawater again, and tested after 4 years from the start of the experiment. Theoretically, smaller O-rings (i.e., ID = $12 \mathrm{~mm}$ ) should experience greater deformation at the polymer-metal interface due to a higher strain, leading to a larger surface area of metal exposed to the stagnant region, while larger $\mathrm{O}$ rings (i.e., ID $=14 \mathrm{~mm}$ ) would retain their original dimensions to a greater extent, as shown in Figure 4. Corrosionresistant 316 stainless steel was used for this case study.

2.2. Case B: The Effect of O-Ring Shape on Metal Corrosion. Round Buna-N O-rings with an internal diameter of $12.3 \mathrm{~mm}$ and quad Buna-N O-rings with an internal diameter of $12.7 \mathrm{~mm}$ (Figure 1) were used to examine the dependence of metal corrosion on O-ring shape. Corrosion-resistant 316 stainless steel was used for this case study.

2.3. Case C: The Effect of O-Ring Composition on Metal Corrosion. Round Buna-N and EPDM O-rings with an internal diameter of $12.3 \mathrm{~mm}$ were used to probe the effect

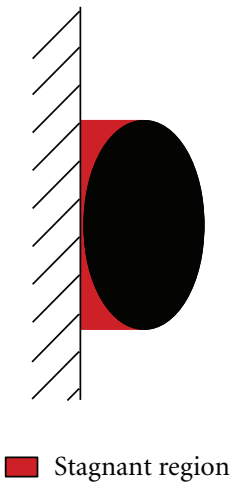

(a)

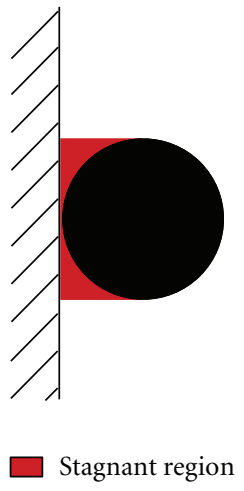

(b)
Figure 4: Deformation of (a) $12 \mathrm{~mm}$ and (b) $14 \mathrm{~mm}$ Buna-N Orings.

of O-ring composition on metal corrosion. Variables such as the percent acrylonitrile (in Buna-N O-rings) or ethylene (in EPDM O-rings), extent of cross-linking between polymer chains, and percentage of fillers such as carbon employed in the O-ring matrix can affect properties such as the modulus of elasticity. Corrosion-resistant 316 stainless steel was used for this case study.

2.4. Case D: The Effect the Metal Identity on the Corrosion Process. Rods containing each of six metal alloys, including corrosion-resistant 316 stainless steel, 4130 steel, aluminum, nickel, titanium, and bronze alloys, were used. Additionally, round Buna-N O-rings with an internal diameter of $12.3 \mathrm{~mm}$ were employed in this case study.

\section{Results and Discussion}

Metal alloys were fitted with polymer O-rings of varying size, shape, and composition to determine the role of the O-ring on metal corrosion. Both crevice corrosion and the buildup of metal oxides such as rust, over the entire surface, were 
TABLE 1: Deformation of Buna-N round O-rings fitted on 316 stainless steel. ${ }^{a}$

\begin{tabular}{|c|c|c|c|c|c|c|}
\hline Entry & O-Ring type & Starting ID (mm) & Final ID (mm) & $\Delta \mathrm{ID}(\mathrm{mm})$ & Crevice corrosion $^{\mathrm{b}}$ & Stainless steel \\
\hline 1 & $\begin{array}{c}\text { Buna-N } \\
\text { round }\end{array}$ & 12 & 13.9 & 1.9 & Severe & \\
\hline 2 & $\begin{array}{l}\text { Buna-N } \\
\text { round }\end{array}$ & 13 & $13.9-14.05$ & $0.9-1.05$ & Moderate & \\
\hline 3 & $\begin{array}{c}\text { Buna-N } \\
\text { round }\end{array}$ & 14 & $15.02-15.12$ & $1.02-1.12$ & Moderate & \\
\hline
\end{tabular}

${ }^{a}$ Data for one $12 \mathrm{~mm}$, two $13 \mathrm{~mm}$, and two $14 \mathrm{~mm}$ O-rings. ${ }^{b}$ none: no observable crevice corrosion under O-ring, low: minimal surface indentation due to crevice corrosion, moderate: small surface indentation, and severe: large surface indentation.

observed in some of the systems described in the following. The presence or absence of either type of corrosion was dependent on the nature of the metal as well as the size, shape, and composition of the O-ring.

\subsection{Case A: The Effect of Contact Stress on Metal Corrosion.} To study the effect of contact stress on metal corrosion, 316 stainless steel samples (Table 1) were fitted with Buna$\mathrm{N}$ round O-rings of varying inner diameters (ID $=12,13$, and $14 \mathrm{~mm}$ ). For each type of O-ring, crevice corrosion was observed at the rubber-metal interface. The 316 stainless steel with the $12 \mathrm{~mm}$ O-ring (Table 1, Entry 1) had the highest contact stress and widest crevice, while the 316 stainless steel with the $14 \mathrm{~mm}$ O-ring sample (Table 1, Entry 3 ) had the lowest contact stress and the narrowest crevice. The width of the crevice (Figure 5), as measured from the widest part of the groove, increased with the strain of the O-ring. It should be noted that the strain of the O-rings in the figure was calculated with the O-ring still fitted on the metal rods. For each stainless steel sample, the crevice size was observed to increase with time from 0.7 to 4 years. As the O-ring's strain increases from an inner diameter (ID) of $14 \mathrm{~mm}$ to $12 \mathrm{~mm}$, both the contact stress and the effective contact area between the O-ring and the metal sample increase. The geometry of the stagnant region plays a large role in crevice corrosion; however, this area can be difficult to define. Tighter gaps resulting in deeper stagnant regions favor the initiation of crevice corrosion [14]. Comparison of the O-ring ID after four years on stainless steel to the starting ID showed a greater change $(\Delta \mathrm{ID})$ for the $12 \mathrm{~mm}$ O-rings. Here the $\Delta \mathrm{ID}$ was measured after the O-rings were removed from the metal rods. The greater $\Delta \mathrm{ID}$ of the $12 \mathrm{~mm} \mathrm{O}$-ring suggests a higher strain compared to the 13 and $14 \mathrm{~mm}$ O-rings, likely resulting in a tighter gap between the $\mathrm{O}$-ring and the stainless steel and therefore increased crevice corrosion.

As shown in Table 1, varying levels of surface oxidation were also observed in the 316 stainless steel samples. The discoloration of the metal surface is likely due to the formation of iron oxides (e.g., $\mathrm{Fe}_{2} \mathrm{O}_{3}$, rust) [15]. In general, the $12 \mathrm{~mm}$ O-ring samples with the greatest amount of crevice corrosion show the most discoloration of the metal surface adjacent to the location of the O-ring. No rust formation was observed in the crevice, which is similar to results observed in cases of pitting corrosion [15]. Metal chlorides and metal hydroxides may leach out of the crevice and ultimately deposit on the surface as the more stable metal oxide.

3.2. Case B: The Effect of O-Ring Shape on Metal Corrosion. To determine the effect of O-ring shape on corrosion (Table 2, Entries 1 and 2), 316 stainless steel was fitted with round and quad Buna-N O-rings. The most significant 
TABle 2: Deformation of Buna-N and EPDM O-rings fitted on 316 stainless steel. $^{a}$

\begin{tabular}{|c|c|c|c|c|c|c|}
\hline Entry & O-Ring & Starting ID $(\mathrm{mm})$ & Final ID (mm) & $\Delta \mathrm{ID}(\mathrm{mm})$ & Crevice corrosion $^{b}$ & 316 stainless steel \\
\hline 1 & $\begin{array}{l}\text { Buna-N } \\
\text { round }\end{array}$ & 12.3 & $14.66-14.99$ & $2.36-2.69$ & Severe & 1 \\
\hline 2 & $\begin{array}{c}\text { Buna-N } \\
\text { quad }\end{array}$ & 12.3 & $13.74-13.80$ & $1.44-1.50$ & Moderate & \\
\hline 3 & $\begin{array}{l}\text { EPDM } \\
\text { round }\end{array}$ & 12.3 & $13.43-13.50$ & $1.13-1.20$ & None & \\
\hline
\end{tabular}

${ }^{a}$ Data for two Buna-N round, two Buna-N quad, and two EPDM O-rings. ${ }^{b}$ none: no observable crevice corrosion under O-ring, low: minimal surface indentation due to crevice corrosion, moderate: small surface indentation, and severe: large surface indentation.

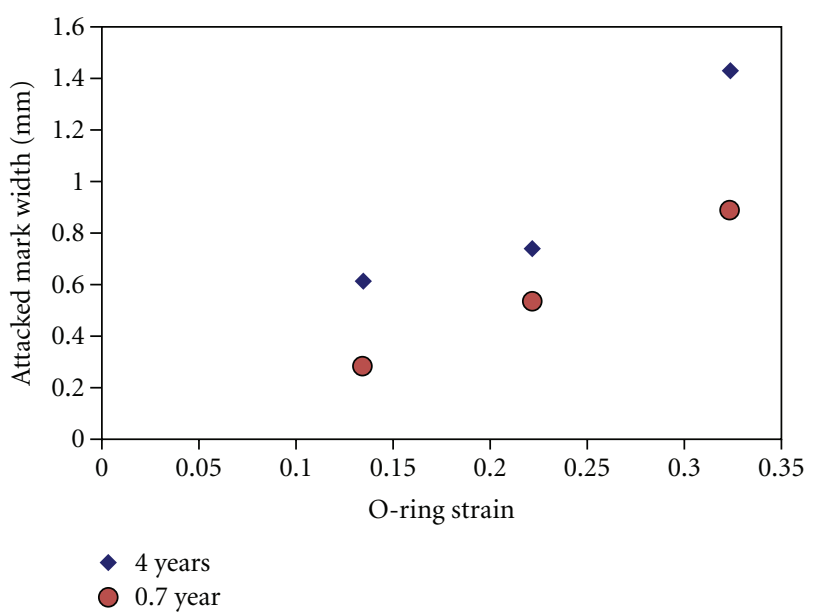

FIGURE 5: Crevice width of stainless steel samples fitted with O-rings of varying strains.

crevice corrosion was observed for the round Buna-N Orings, which exhibited more significant deformation than the quad O-rings. The $\Delta \mathrm{ID}$ of the round Buna-N O-rings (Table 2, Entry 1) was greater than the $\Delta \mathrm{ID}$ for the quad Buna-N O-rings (Table 2, Entry 2). The shape of the O-ring drastically impacts the geometry of the stagnant region and therefore the crevice formation. Based on these experimental results, the quad Buna-N O-rings lead to decreased crevice formation on 316 stainless steel, when compared to similar round Buna-N O-rings.

Varying levels of surface oxidation were also observed in these 316 stainless steel samples. The 316 stainless steel samples bearing the round Buna-N O-rings displayed increased discoloration compared with the samples fitted with quad Buna-N O-rings. As with Case A, the samples with the greatest crevice corrosion also displayed the most rust formation.

3.3. Case C: The Effect of O-Ring Composition on Metal Corrosion. To study the effect of the O-ring composition on metal corrosion, 316 stainless steel rods were fitted with O-rings of varying polymer composition (Table 2). No oxidation products or crevice corrosion was observed for the combination of EPDM rubber O-rings and 316 stainless steel (Table 2, Entry 3). Alternatively, the round Buna-N O-rings caused severe corrosion at the rubber-stainless steel interface (Table 2, Entry 1). For all O-rings tested, the weight of the Orings soaked for four years in salt water was compared to the weight of dry new O-rings. No observable change in O-ring 


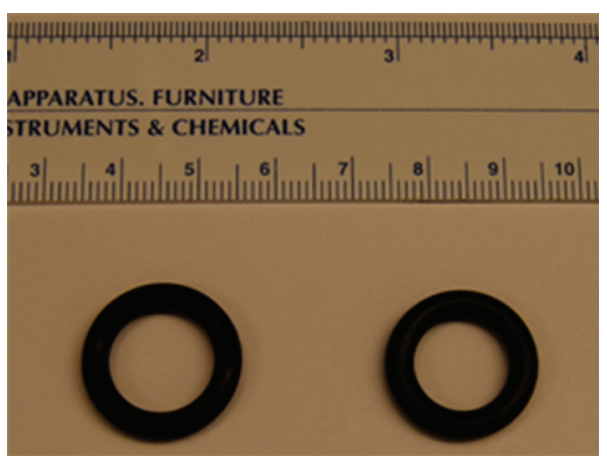

(a)

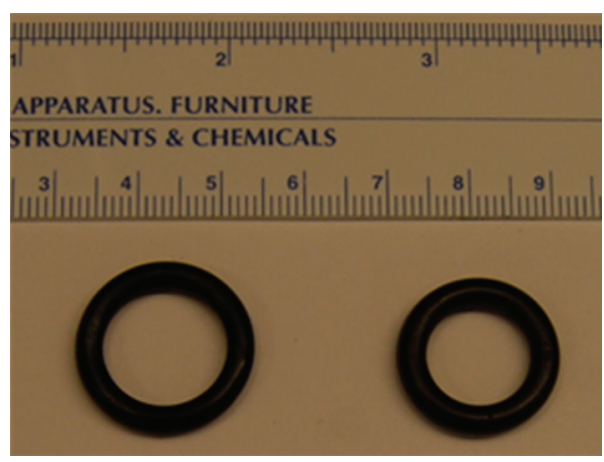

(b)

Figure 6: Change in internal diameter ( $\triangle \mathrm{ID}$ ) for (a) EPDM and (b) Buna-N O-rings.

weight was observed for either the EPDM or the Buna-N Orings, and therefore swelling of the polymer samples is not a likely reason for the difference in crevice corrosion.

For O-ring samples of the same size and weight, considerable difference was observed for the deformation of the EPDM and Buna-N O-rings. EPDM showed the lowest overall $\Delta \mathrm{ID}(1.13-120 \mathrm{~mm}$, Figure 6), whereas the Buna-N Orings displayed a much larger $\Delta \mathrm{ID}(2.36-269 \mathrm{~mm}$, Figure 6). As with the previous cases, greater deformation of the $\mathrm{O}$ ring led to the most crevice corrosion. A variety of factors could influence the amount of deformation a given polymer sample will exhibit. For Buna-N O-rings, increasing the acrylonitrile content in the polymer decreases the elastic behavior. Similarly, increasing the ethylene content in EPDM results in an increase in the crystalline regions present in the polymers. For both Buna-N and EPDM, the type of filler as well as the percent cross-linking due to vulcanization will also affect the mechanical properties and therefore deformation of the O-ring [9]. In an effort to determine what, if any materials are leaching out of the O-rings, round and quad Buna-N and round EPDM O-rings were immersed in deuterated water. In each case, an identical sample was placed in a solution of $\sim 3 \% \mathrm{NaCl}$ in deuterated water. After one month in solution, ${ }^{1} \mathrm{H}$ nuclear magnetic resonance (NMR) spectroscopy showed no sign of proton-containing leachate in solution, with the exception of the round Buna$\mathrm{N}$ O-ring, which displayed a small singlet at $5.57 \mathrm{ppm}$. This peak may be attributed to a low-molecular-weight leachate, though the sharp signal and lack of additional resonances suggest that this may be an impurity or filler in the Oring, rather than an oligomer, or the result of polymer degradation. These results further support the claim that leaching and swelling of the O-rings are not a factor in the observed metal corrosion. Considering these factors together makes it difficult to pinpoint a single reason for the difference in deformation between the EPDM and Buna-N O-rings.

Varying levels of rust formation were observed in the 316 stainless steel samples. No observable discoloration or crevice corrosion was observed in the 316 stainless steel samples bearing the EPDM O-rings. Alternatively, the most rust formation and crevice corrosion were found in the 316 stainless steel samples fitted with round Buna-N O-rings. Consistent with the previous cases, the samples with the greatest crevice corrosion also displayed the most discoloration.

3.4. Case D: The Effect of the Metal Identity on the Corrosion Process. To study the effect of the metal alloy on corrosion (Table 3), a variety of different metals were fitted with round Buna-N O-rings (12.3 mm ID). Both the titanium (Table 3, Entry 1) and nickel (Table 3, Entry 2) samples show very little surface oxidation or crevice corrosion. Nickel alloy 625 contains high percentages of elements such as nickel (54-68\%) and molybdenum (8-10\%) that are known to confer corrosion resistance [15]. Similarly, titanium alloys have also been found to exhibit high resistance to crevice corrosion in marine applications [16]. For 316 stainless steel (Table 3, Entry 3), crevice corrosion can be observed at the rubber-metal interface as well as surface oxidation on either side of the interface. The 316 stainless steel samples contain a significant amount of iron (62-72\%), which can account for the surface discoloration and rust formation. The presence of molybdenum (2-3\%), nickel (10-14\%), and chromium (16-18\%) increases the corrosion resistance of 316 stainless steel and explains why extensive corrosion is not observed [15]. The 4130 steel samples (Table 3, Entry 4) showed severe corrosion over the entire surface of the metal, with significant rusting, though significant crevice corrosion was not observed. 4130 steel contains only small amounts of corrosion resistant metals (molybdenum $=0.15$ $0.25 \%$, chromium $=0.80-1.10 \%)$ and a high percentage of iron (97-98\%) resulting in formation of large rust deposits over the entire sample. The bronze samples (Table 3, Entry 5) also showed significant evidence of corrosion on the surface of the rod, though not in the crevice. Surface deposits for the bronze samples had a green appearance characteristic of copper oxide, in keeping with the high copper content ( $89 \%$ ) for this alloy. No evidence of corrosion was observed at the site of the O-ring for the bronze samples, suggesting that the O-ring formed an effective barrier against surface corrosion, without promoting crevice corrosion. Similarly, the aluminum alloy (Table 3, Entry 6) also showed evidence of significant corrosion over the entire surface of the sample. 
TABLE 3: Crevice corrosion and surface oxidation of varying metal alloys fitted with round Buna-N O-rings. ${ }^{a}$

\begin{tabular}{|c|c|c|c|c|c|}
\hline Entry & Metal & $\mathrm{pH}$ range & Crevice corrosion $^{\mathrm{b}}$ & Surface oxidation $^{\mathrm{c}}$ & Metal alloy \\
\hline 1 & Titanium alloy & $5.64-6.14$ & None & None & \\
\hline
\end{tabular}
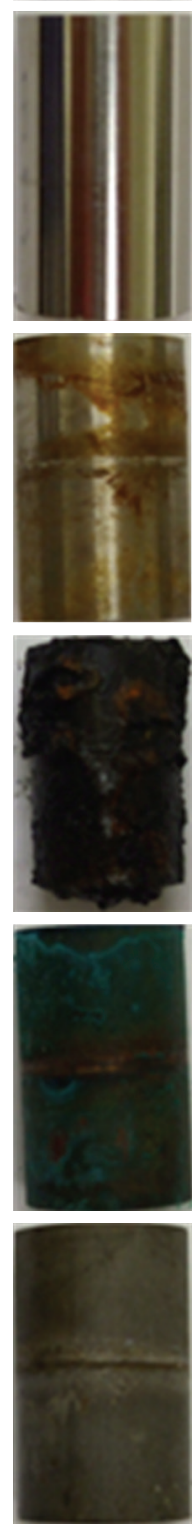

${ }^{\mathrm{a}}$ Data for three samples of each metal alloy. ${ }^{\mathrm{b}}$ none: no observable crevice corrosion under O-ring, low: minimal surface indentation due to crevice corrosion, moderate: small surface indentation, and severe: large surface indentation. ${ }^{c}$ none: no observable oxidation over entire surface of metal, low: $0-25 \%$, moderate: $25-75 \%$, and severe: $75-100 \%$.

The O-ring again acted as again effective barrier against corrosion.

Measurement of the saltwater solution pHs revealed that the metal alloys with the most extensive surface oxidation (bronze, aluminum, and 4130 steel) had the highest $\mathrm{pH}$ values, in keeping with observations by Aballe and coworkers [17]. Systems that are more resistant to corrosion (316 stainless steel, nickel, and titanium alloys) exhibited lower $\mathrm{pH}$ values. Of the six metal alloys, only the 316 stainless steel samples showed significant crevice corrosion. 


\section{Conclusions}

Four sets of experiments have been conducted to study the effect of O-ring size, composition, and shape, as well as alloy composition/identity on the extent of metal corrosion in an artificial saltwater solution. Crevice corrosion was found to occur most prevalently in 316 stainless steel samples combined with Buna-N O-rings and is theorized to arise as a result of stagnant regions near the polymer-metal interface region. In some cases, differences in the extent and severity of crevice corrosion at the O-ring site may be attributed to the size or shape of the O-ring employed. In general, polymer Orings showing the greatest deformation exhibited the most crevice corrosion. The composition of the O-ring played an important role in the amount of crevice corrosion. Buna$\mathrm{N}$ O-rings resulted in the most crevice corrosion, whereas EPDM O-rings of the same size and shape did not lead to any crevice corrosion for 316 stainless steel. The extent of surface corrosion was governed mainly by the composition of the metal alloy, rather than being dependent on the composition or size of the rubber O-ring used. Further studies to determine the dependence of metal corrosion on the size, shape, and material composition of polymeric seals are underway and will be reported in due course.

\section{Conflict of Interests}

None of the authors have any conflict of interests regarding this work.

\section{Acknowledgments}

H. Shen acknowledges the financial support in the form of a grant from the National Science Foundation (DMR0423914). A. M. Anderson-Wile and B. M. Wile acknowledge the financial support from The Getty College of Arts and Sciences at Ohio Northern University. William Kanzig is thanked for support and useful discussions.

\section{References}

[1] A. Naganuma and K. Azumi, "Observation of corrosion behavior of stainless steels in a salt manufacturing plant environment using the multichannel electrode method," Corrosion Science, vol. 53, no. 4, pp. 1165-1173, 2011.

[2] W. Wang, X. Zhang, and J. Wang, "Rainbow fringes around crevice corrosion formed on stainless steel AISI 316 after ennoblement in seawater," Materials and Corrosion, vol. 60, no. 10, pp. 820-824, 2009.

[3] G. Mori and D. Bauernfeind, "Pitting and crevice corrosion of superaustenitic stainless steels," Materials and Corrosion, vol. 55, no. 3, pp. 164-173, 2004.

[4] Z. Li, F. Gan, and X. Mao, "A study on cathodic protection against crevice corrosion in dilute $\mathrm{NaCl}$ solutions," Corrosion Science, vol. 44, no. 4, pp. 689-701, 2002.

[5] P. T. Jakobsen and E. Maahn, "Temperature and potential dependence of crevice corrosion of AISI 316 stainless steel," Corrosion Science, vol. 43, no. 9, pp. 1693-1709, 2001.

[6] G. F. Kennell and R. W. Evitts, "Crevice corrosion cathodic reactions and crevice scaling laws," Electrochimica Acta, vol. 54, no. 20, pp. 4696-4703, 2009.
[7] G. F. Kennell, R. W. Evitts, and K. L. Heppner, "A critical crevice solution and IR drop crevice corrosion model," Corrosion Science, vol. 50, no. 6, pp. 1716-1725, 2008.

[8] G. B. Kauffman and R. B. Seymour, "Elastomers: II. Synthetic rubbers," Journal of Chemical Education, vol. 68, no. 3, pp. 217-220, 1991.

[9] W. Hofmann, Rubber Technology Handbook, Hanser, New York, NY, USA, 1989.

[10] A. Y. Coran, "Chemistry of the vulcanization and protection of elastomers: a review of the achievements," Journal of Applied Polymer Science, vol. 87, no. 1, pp. 24-30, 2003.

[11] P. E. Schweitzer, Corrosion Resistance of Elastomers, Marcel Dekker, New York, NY, USA, 1990.

[12] J. R. White and S. K. De, Eds., Rubber Technologist's Handbook, Rapra Technology, Shawbury, UK.

[13] S. Mitra, A. Ghanbari-Siahkali, P. Kingshott, H. K. Rehmeier, H. Abildgaard, and K. Almdal, "Chemical degradation of crosslinked ethylene-propylene-diene rubber in an acidic environment. Part I. Effect on accelerated sulphur crosslinks," Polymer Degradation and Stability, vol. 91, no. 1, pp. 69-80, 2006.

[14] A. J. Sedriks, Corrosion of Stainless Steels, John Wiley \& Sons, New York, NY, USA, 2nd edition, 1996.

[15] Y. Tsutsumi, A. Nishikata, and T. Tsuru, "Pitting corrosion mechanism of Type 304 stainless steel under a droplet of chloride solutions," Corrosion Science, vol. 49, no. 3, pp. 13941407, 2007.

[16] I. V. Gorynin, “Titanium alloys for marine application,” Materials Science and Engineering A, vol. 263, no. 2, pp. 112-116, 1999.

[17] A. Aballe, M. Bethencourt, F. J. Botana, M. J. Cano, and M. Marcos, "Localized alkaline corrosion of alloy AA5083 in neutral 3.5\% NaCl solution," Corrosion Science, vol. 43, no. 9, pp. 1657-1674, 2001. 

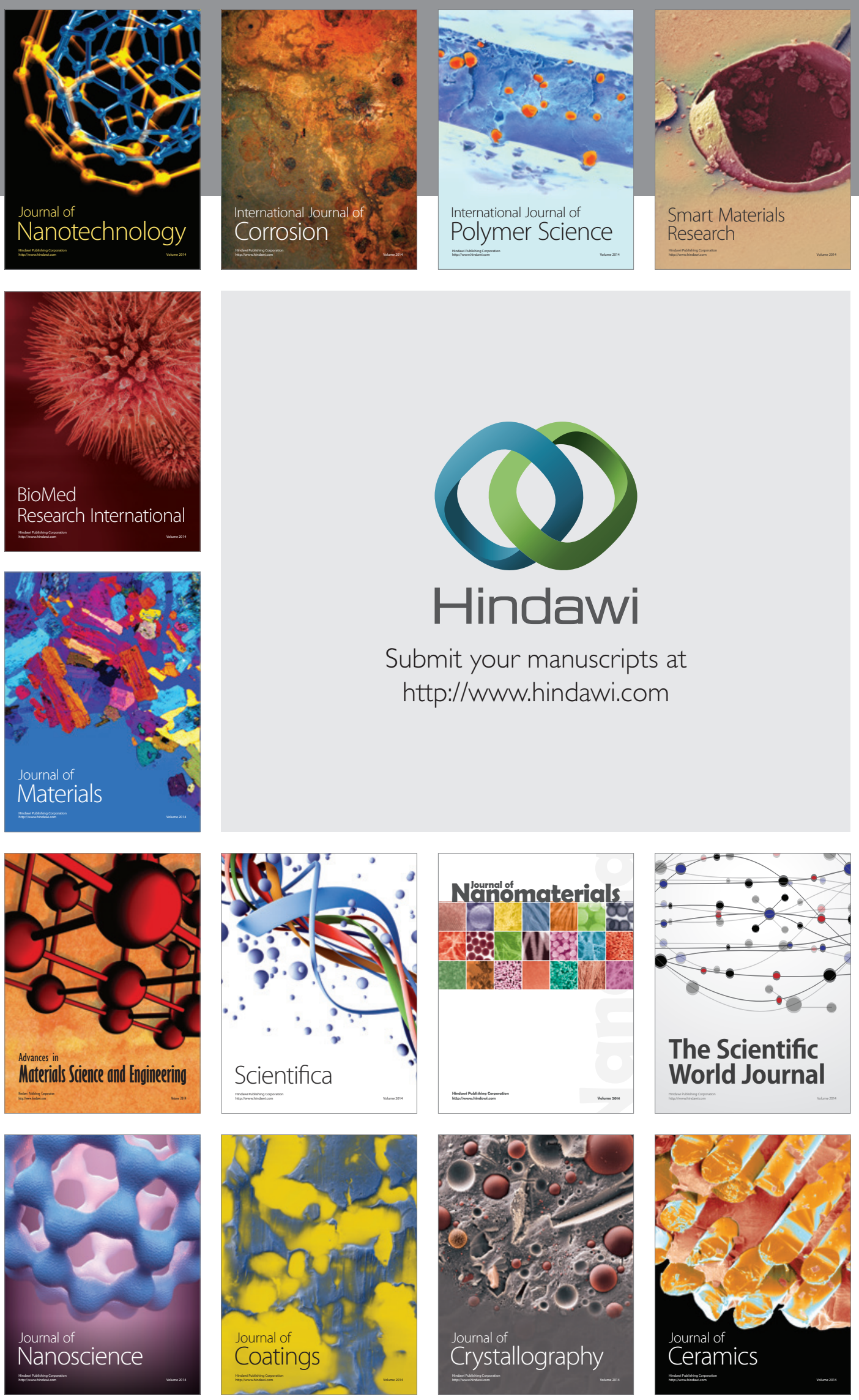

The Scientific World Journal

Submit your manuscripts at

http://www.hindawi.com

\section{World Journal}

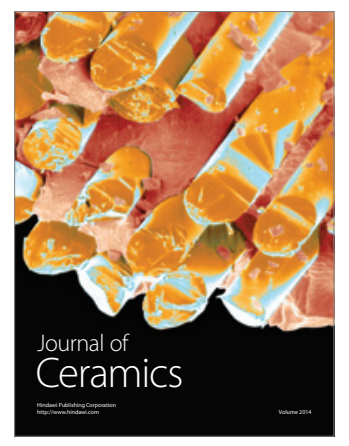

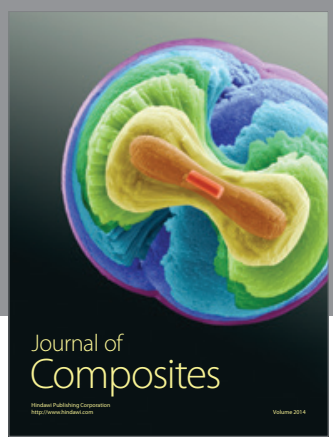
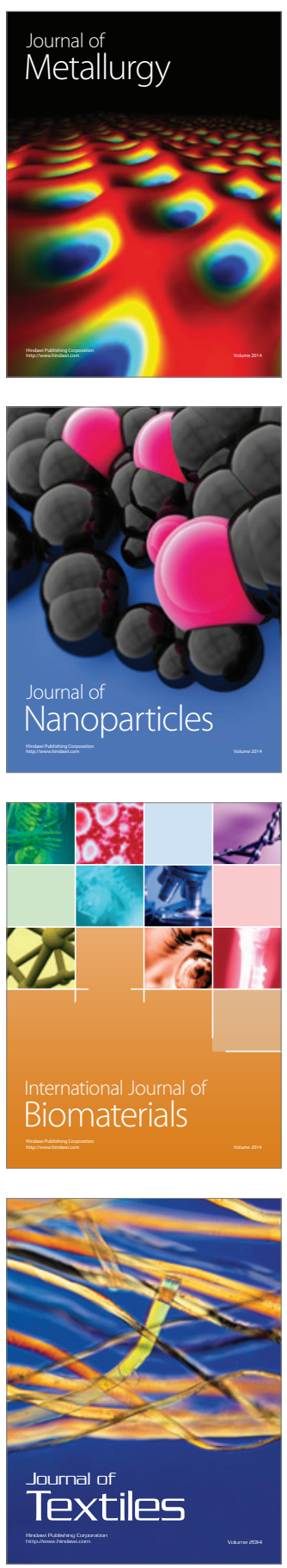